\title{
Effect of a Rotor Wake on the Local Heat Transfer on the Forward Half of a Circular Cylinder
}

Kim A. Morehouse and Robert J. Simoneau

Lewis Research Center

Cleveland, Ohio

March 1986

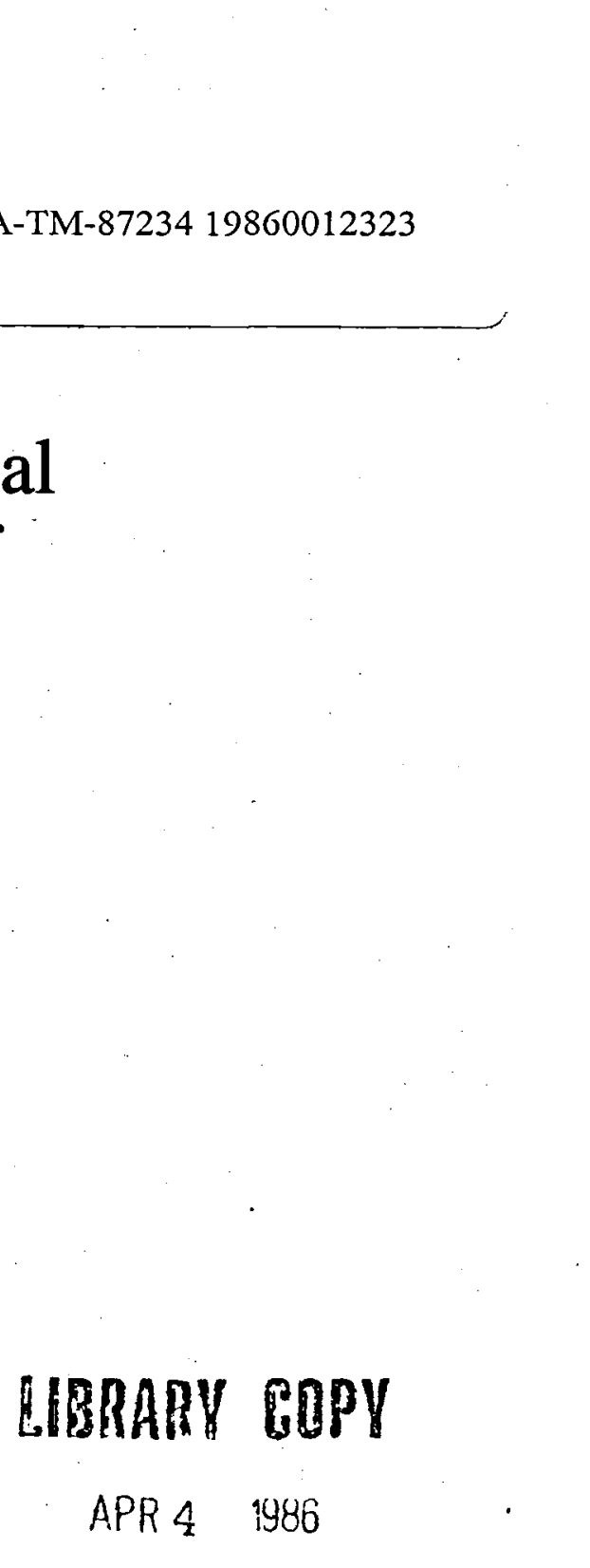

AM-87234 19860012323
LANGLEY RESEARCH CENTER

LIBRARY, NASA

HIAM:PTON, VIRGINIA 


\section{EFFECT OF A ROTOR WAKE ON THE I.OCAL HEAT TRANSFER ON THE}

\section{FORWARD HALF OF A CIRCULAR CYI.INDE.R}

Kim A. Morehouse and Robert J. Simoneau

National Aeronautics and Space Administration

Lewis Research Center

Cleveland, ohio 44135

\section{SUMMARY}

An experiment has been developed to simulate the wake dynamics of a tur. bine rotor stator combination. The experiment consisted of a spoked whecl rotating in annular flow, generating simulated rotor wakes. The wakes impinged on a simulated stator, composed of a circular cylinder with a splitter plate behind it. The test rig properly simulated the wake shapes and velocity dynamics of a rotating turbine stage. The focus of the research was spanwise averaged circumferentially local heat transfer in the circular cylindrical leading edge region of a turbine alrfoil. The range of Reynolds number based on the stator cylinder diameter was 35000 to 175000 . The reduced blade pas sing frequencies, or Strouhal numbers, also based on the stator cylinder diam. eter, ranged from 0.63 to 2.50. The wakes were generated by two different sets of circular cylindrical bars, 1.59 and $3.18 \mathrm{~mm}$ in diameter. The rotor could be rotated either clockwise or counterclockwise, causing the wakes to impinge on either the leeward or the windward side of the heated cylinder. addition, grid turbulence was introduced upstream yielding rreestream turbu lence of 1.0 to 2.5 percent at the stator location.

The data presented in this paper, therefore, represent an extensive body of local heat transfer coefficients, which can be used to develop models in the very important leading edge region of a turbine airfoil. The wakes pro. duced only a modest increase in heat transfer over the baseline no rotor data. The data in the presence of the rotor wakes showed an asymmetry from the lee. ward to the windward side. Windward side levels of from 30 to 40 percent higher than corresponding leeward-side levels were not uncommon, particularly at the combination of high Strouhal number and larger wake generating $p$ ins. The stagnation gauge data were examined against the lu $\sqrt{\mathrm{Re}}$ parameter over a wide range from 8 to 40 , and found not to bc fully correlated by this of ten used parameter. There were distinct trends with both rec-stream turbulence level and wake-generating bar diameter. The results strongly indicate a need to separate the wake influence rrom turbulence effects.

\section{INTRODUCTION}

Considerable effort is being directed these days at heat transfer in unsteady flow fields. Probably among the oldest unsteady effects studied are those which occur naturally in the flow, such as one body in the wake of

*A shortened version of this report will be presented at the 8 th International Heat 1 ransfer Conference, San Francisco, California, August $1 \%-22,1986$. 
another or the effect of natural instabilities. Another area involves oscil. lations of the entire flow field, such as might occur downstream of a pump. A third type of unsteadiness, the type of interest herein, is a forced, periodic and localized, disturbance of the flow, such as occurs where a moving object cuts across the flow path, as in a turbine.

Research on heat transfer in these flow fields is just beginning. Work includes heat transfer in turbines (refs. 1 to 4 ), as well as in the wakes of spoked wheel or squirrel cage disturbance generators (refs. 5 to 9). The exact nature of the moving wakes on heat transfer awaits more research; however, in general it can be said that these disturbances enhance heat transfer. The passing of the wakes can produce some dramatic local unsteady heat transfer effects, as shown by Doorly and 0ldfield (ref. 6), Ashworth et al., (ref. 7). The effect on steady heat transfer, especially when combined with normal turbu lence, is not uniformly clear, as shown by Dunn (refs. 1 to 3 ), for example.

There is a growing opinion which suggests that it will be necessary to sort out the periodic unsteadiness from the random turbulence. Jayaramon, Parikh, and Reynolds (ref. 10) propose a triple decomposition of the velocity vectors. Adamczyk (ref. 11) also recommends changes in turbomachinery closure modeling. The extend and detail of what must be done will be evolving for sometime.

The experiment reported herein simulated a turbine rotor wake with a rotating spoked wheel. The leading edge of the airfoil in the wake was simulated with a circular cylinder with a splitter plate behind it. Spanwise averaged, circumferentially local heat transfer was measured for angles from $0^{\circ}$ to $79^{\circ}$ from stagnation on both the windand leeward side relative to the convected wake. Reference data were acquired at various turbulence levels with the rotor removed. An attempt is made to sort out the two effects.

NOMENCLATURE

A cross sectional area, $\mathrm{m}^{2}$
$\mathrm{~A}_{\mathrm{s}}$ surface area, $\mathrm{m}^{2}$
$\mathrm{~d}$ diamter, $\mathrm{m}$
$f \quad$ frequency, $\mathrm{Hz}$
$\mathrm{l} \quad$ current, amps
$\mathrm{k} \quad$ thermal conductivity, $\mathrm{w} / \mathrm{m}^{2} \mathrm{~K}$
$\mathrm{~m} \quad$ mass $\mathrm{flux}, \mathrm{kg} / \mathrm{m}^{2} \mathrm{sec}$
$\mathrm{Nu} \quad$ Nusselt number, dimensionless
$\mathrm{Pr} \quad$ Prandtl number, dimensionless
$\mathrm{Q} \quad$ heat, power, $\mathrm{w}$

Re Reynolds number, dimensionless 


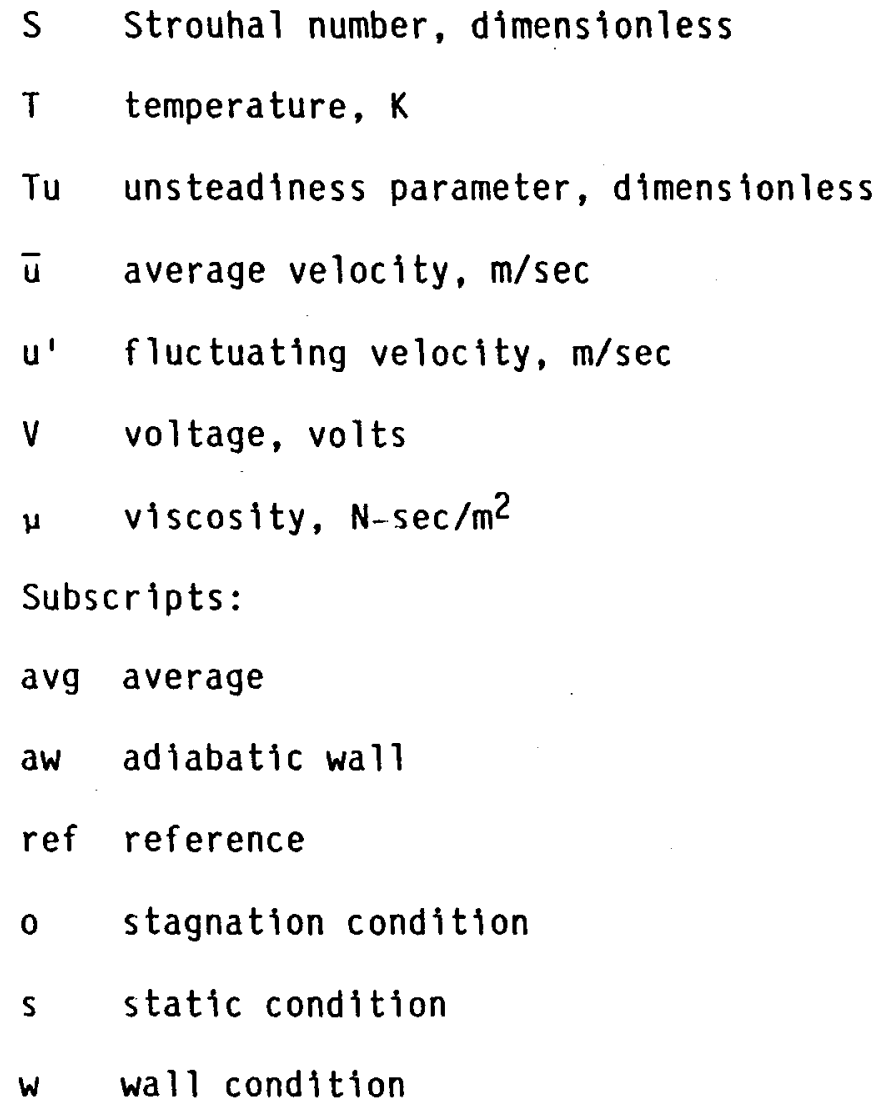

ROTOR WAKE SIMULATION

The simulation employed in this experiment is illustrated in figure 1. In part (a) a typical turbine stage with the wake-related velocity triangles is shown. Only two points are important. First, whether one is looking at the rotor passing into a stator wake or a rotor wake being carried into a stator passage, the effect is the same. The suction surface sees the wake first and the change in incidence is towards negative incidence. The simulation produced by a circular rod passing across the flow field is shown in part (b). The major features are clearly the same.

The simulation used in the present experiment is illustrated in figure 2. A spoked wheel rotates in an annular flow passage producing the desired wakes. Since the focus is on the leading edge region, the downstream airfoil is even further simplified by using a circular cylinder with a splitter plate behind it to eliminate alternate shedding vortices.

Typical instantaneous and ensemble-averaged wakes produced in the simulation rig (more information on them appears in ref. 5) are shown in figure 3. The combination of the turbulence and the periodic unsteadiness is apparent in figure $3(a)$. The random components disappear in the averaging process, figure $3(b)$. These wakes were compared to compressor wakes measured by Evans (ref. 12) and found to exhibit a 11 the major features of depth, width and so on. 


\section{DESCRIPTION OF EXPERIMENT}

The key element in the present experiment is the segmented copper heat transfer cylinder, shown in figure 4. The test section was a $2.62 \mathrm{~cm}$ diameter circular cylinder composed of 15 individually controlled heater elements, which served as heat transfer gauges. Each heater was made of a solid copper bar with a thermocouple (Type E) buried near the surface and a heater element at the back. The temperature signal from each element was fed into an electronic control circuit, described in reference 13, which controlled the power to each heater such that the temperature of all elements was held constant to within $0.1 \mathrm{~K}$. Thus, the experiment is an isothermal wall boundary condition. Twelve of the heater elements were spaced around the cylinder circumference at nomi. nally $11^{\circ}$ increments, as can be seen in figure 4. The two end elements served as guard heaters, leaving 10 active heat transfer elements. Both of the span. wise ends had a guard heater, as shown. The back of the whole assembly was also guarded. This element, of course, cannot be seen in the photograph. Each of the active heat transfer elements was $2.50 \mathrm{~mm}$ wide by $33.0 \mathrm{~mm}$ long. Each element had a mylar and epoxy insulating space between them. It can be seen from the photograph that the installation was not perfectiy equispaced. (It must be remembered that all 15 elements with heater lead wires and thermo couples for each were stuffed into a package only $2.62 \mathrm{~cm}$ in. diam.) The actual center-to-center spacing was measured and these actual angles are used in the data reporting. The photograph, figure 4 , was taken after the experi. ment and shows a small nick in one of the heaters. This occurred midway through the experiment, when the sinaller pins broke. It appeared to have no effect on the subsequent data.

The circumferentially segmented heated test cylinder was installed in the rotor-wake rig, shown in figure 5 , at a distance $2.5 \mathrm{~cm}$ downstream of the spoked rotor. Thus, the wakes were being generated one stator diameter upstream of the stator stagnation line. The flow facility and its characteri stics are described in some detail in reference 5. Only those details essen. tial to the present experiment will be described herein. The flow facility was at room temperature and pressure annular flow wind tunnel. The flow annu. lus was $40.6 \mathrm{~cm} 0 . d$. by $27.1 \mathrm{~cm} \mathrm{i.d.,} \mathrm{providing} \mathrm{a} 0.722 \mathrm{~m}^{2}$ flow cross section. The heated cylinder was one of eight stators equispaced circumfercntially around the annulus, each with a $1.6 \mathrm{~mm}$ thick splitter plate behind, as illu. strated in figure 2. The heated stators provided a 20 percent flow blockage. The wake generating rotor was a spoked wheel of 24 cylindrical pins, as $111 \mathrm{l}$ strated in figure 2. There were two pin diameters, $1.59 \mathrm{~mm}$ and $3.18 \mathrm{~mm}$. The rotor was driven with a motor and pulley arrangement. It could be driven both forward and reverse and could be controlled at specds from s00 to $7300 \mathrm{rpm}$. The turbulence was controlled with square pattern woven wire screcrs with approximately two thirds open area. Two grid sizes, 10.mesh and 3.mesh, were used. (The $x$-mesh terminology is an American wire manufacturer designation standing for $x$ wires per inch and does not translate well to sl units. For convenience this jargon will be used herein.) The 3 -mesh grid had $1.6 \mathrm{~mm}$ wires spaced about $8.5 \mathrm{~mm}$ apart and the 10 mesh grid had $0.25 \mathrm{~mm}$ wires spaced about 2.5 mim apart. Except for one dataset the grids were located $21.0 \mathrm{~cm}$ upstrearn of the stator leading edge. (In one case the 3 -mesh grid was located $10.8 \mathrm{~cm}$ upstream.)

As indicated above, the heat transfer from each element was determined by measuring the power delivered to each individual backside heater and the temp erature of the copper element with a thermocouple buried in it. The tunnel 
mass flow rate was measured with a sharp edged orificed designed to ASME standards. This measurement was backed up by treating the inlet contraction as on isentropic nozzle. Velocity was measured at two locations, one half way between the turbulence grid and the stator plane and the other at the stator stagnation plane, using a pilot-static probe. Velocities and turbulence intensities were also measured at the same locations with single-wire hot wire anenometers. The rotor speed was measured with a fiber optic probe sighted on the tip of one of the rotor pins painted white. This was backed up by a 60-tooth gear and magnetic pickup on the rotor drive shaft.

The data are presented in terms of Nusselt, Reynolds and Strouhal numbers and also an unsteadiness or turbulence parameter, all defined below.

The Reynolds number is based on a mass-averaged velocity and free-stream properties.

$$
\operatorname{Re}=\frac{m d}{A_{\mu}}
$$

The Strouhal or reduced frequency is based on the rotor circular frequency and the same mass-averaged velocity. Expressed in terms of the rotor pin (blade) passing frequency it is:

$$
S=\frac{2 \pi f d}{\ddot{u}}
$$

The Nusselt number is defined in the following manner.

$$
N u=\frac{\left(Q_{\text {tot }}-Q_{\text {loss }}\right) d}{\left(T_{w}-T_{a w}\right) A_{s} k}
$$

The total heat flux is based on the total power dissipated, VI. The heat loss correction has two components; the radiation loss, which was usually quite small, and the loss through the insulating strips, which was occasionally large and varied from strip to strip. The insulation loss was determined analytically, based on a model presented in reference 13. The adiabatic wall temperature assumed a laminar flow Prandt 1 number relationship

$$
T_{\text {aw }}=T_{0}-\sqrt{\operatorname{Pr}}\left(T_{0}-T_{s}\right)
$$

and the thermal conductivity was calculated on the basis of the Eckert (ref. 14) reference temperature

$$
\left.T_{\text {ref }}=0.50 \mathrm{~T}_{\mathrm{w}}\right)_{\mathrm{avg}}+0.28 \mathrm{~T}_{\mathrm{s}}+0.22 \mathrm{~T}_{\mathrm{aw}}
$$

Finally, an unsteadiness parameter is defined as

$$
T u^{\prime}=\frac{u_{r m s}^{\prime}}{\bar{u}}
$$


The unsteadiness is simply the root-mean-square of the velocity flucations divided by the integrated time average of the velocity, as measured by the hot wires. In the absence of the rotor wakes it is the familiar turbulence intensity, Tu. In the wake of the rotor it includes both the random turbulence and the periodic unsteadiness of the wakes, as shown in figure 3 .

An uncertainty analysis, based on the method of Kline and McClintok (ref. 15), was included in the data reduction program and every dataset included uncertainty estimates. These will be shown on the results figures, as appropriate. While the uncertainty varied from run to run, and in the case of Nusselt number from heater strip to heater strip, the average values were: Nusse 1t number 6 percent, Reynolds number 1 percent, Strouhal number 1 percent, and unsteadiness parameter 1 percent.

Finally, before initiating the experiment, flow angle measurements were made behind the rotor. An example for the $1.59 \mathrm{~mm}$ pins is available in reference 5. For both pin sizes the combinations of Reynolds and Strouhal selected were such that the flow angle was always less than $3^{\circ}$.

\section{RESULTS}

\section{No Rotor Reference Cases}

In order to establish a reference database, and to compare existing data to the literature a series of cases were run with the spoked rotor removed. In the first case the heated cylinder was rotated to various angular positions, causing different elements to be the stagnation gauge, in order to see if there was any gauge bias. The results, shown in figure 6 , show very little sensi. tivity to gauge position except for one case at the lowest Reynolds number. The variation from gauge to gauge was well within the average uncertainty band of the stagnation gauge, which is included on the figure. One will note that, except at the stagnation point, the data do not line up with the angles. This is because, as explained earlier, the gauges are not spaced at equal angles; and, when the cylinder is rotated, the angle relative to stagnation changes. There appears to be a slight dip in heat transfer in the stagnation region. Since the dip is within the uncertainty band, one must be cautious in drawing conclusions. However, the dip appears to be independent of gauge selection and has been observed by others (ref. 16).

In order to obtain data over a large angle range $\left(0^{\circ}\right.$ to $\left.79^{\circ}\right)$ gauge 8 was selected to be the stagnation gauge. It was selected over number three, because the uncertainty was always lower. With this choice all the remaining data were acquired with gauge 8 on the stagnation line. This left two active gauges to the opposite side as a check. In the following figures only the eight gauges to one side of stagnation will be shown to avoid confusion.

The no rotor data over the full Reynolds number range of the experiment are shown in figure 7. The error band for each gauge is shown for one of the Reynolds numbers, as typical. The data represent two turbulence levels, approximately 1 percent and 2 percent. For each level, higher Reynolds numbers yielded slightly lower turbulence intensity. The doubling of turbulence inten. sity from 1 to 2 percent leads to a 5 to 10 percent increase in heat transfer, this increase being greater at the higher Reynolds number. The increase is 
pretty uniform for all angles. These data form a baseline reference for the rotor-wake cases.

Despite the large body of data on heat transfer to cylinders in crossflow, when one wishes to make comparisons, it is difficult to find datasets which matchup all conditions. For comparison to the present data the experiments of Kestin and Wood (ref. 17), Vanfossen (ref. 18) and Giedt (ref. 18) were used. The comparisons are shown in figure 8 , for Reynolds numbers in the range of 95000 to 100000 . A third dataset, with higher turbulence level, was added to the data already shown on figure 7 for $R e=97200$. These data were obtained with the 3 -mesh grid only $10.8 \mathrm{~cm}$ from the heater cylinder, as was mentioned above. Although the data of Kestin and Wood (ref. 17) were actually mass transfer sublimation data, the flow conditions most closely match the present data. The comparison is quite good except at the large angles. The data of Van Fossen (ref. 18) agree very well but his data only go out to $50^{\circ}$. The turbulence for these data were generated with parallel wires rather than a square mesh grid. The comparison with Giedt (ref. 19) is less satisfactory both in level and angular dropoff. Giedt's data were uniform heat flux rather than uniform temperature. Papell (ref. 20) showed that uniform heat flux data dropoff more slowly than uniform temperature, which could explain the observed angle variation. The level, especially at stagnation is harder to explain, except that Giedt estimated his turbulence intensity, while all the others measured it. In general, within experimental uncertainty, the present data agree well with the literature, well enough at least to draw valid comparisons between the no-rotor and rotor-wake data in the same experiment.

\section{Rotor Wake Data}

A very extensive dataset was acquired in the present experiment, more than can be presented herein. A selected subset is shown in figure $g(a)$ to (d). Two midrange Reynolds numbers and all three Strouhal numbers are presented. Each plot is for a different combination of pin diameter and turbulence grid, four in all. In addition, each plot includes data from wakes produced by both forward and reversed motion of the spoked rotor. A small diagram of the geometry of the flow field is shown on each plot. For the data to the left of center the wake is convected in at the heat transfer gauges (i.e., the windward side) and to the right of center the gauges are in the shadow of the convected wake (i.e., the leeward side). Recall, the wake flow angles are always less than $3^{\circ}$. In terms of the simulation the left hand (windward) data would represent the suction surface of a turbine airfoil and the right hand (leeward) the pressure surface.

Examining figures 9 (a) to (d), one is struck by the strong similarity from case to case. The effects of Strouhal number are small but systematic. Although the effects are on the same order of the uncertainty bands, the fact that they are so consistently systematic is probably relavant. There is a definite asymetry in the data, especially at the higher strouhal numbers and with the larger pins.

In order to get a better appreciation for the various effects, a cross plot of the data was used. The data for one Reynolds number (125 400) and one Strouhal number (1.27) are plotted for all four pins and grid combinations. In addition the no-rotor data are plotted, including the highest turbulence (grid at $10.8 \mathrm{~cm}$ ) case. To aid in comparison the no-rotor data are plotted to 
both the right and left of zero on figure 10. They are not two datasets. Thus, gauge 7 data appears at $\pm 10^{\circ}$, gauge 6 data at $\pm 25^{\circ}$, and so on. The average uncertainty band for the stagnation gauge is shown on the figure. Many of the observations to be made fall within this band.

First, let us focus on the data associated with the 10-mesh grid. In the stagnation region the rotor-wake data show a very modest ( 6 to 7 percent) increase in heat transfer, which is within the uncertainty. In fact, the small-pin data are higher than the large-pin, which does not seem right. Nevertheless, the data are higher. On the leeward side these modest increases persist over the whole angle range. On the windward side, as the flow progresses to higher angles, a more substantial wake-induced increase in heat transfer occurs, reaching almost 50 percent over the no-rotor data at $79^{\circ}$. This is, of course, near separation. However, except at the $79^{\circ}$ point, all of the 10-mesh data fall below the no-rotor 3 -mesh data sets. This, despite the fact that the wake related turbulence/unsteadiness rms is approximately 5 percent for the $1.59 \mathrm{~mm}$ pins and 9 percent for the $3.18 \mathrm{~mm}$ pins. In fact, an almost doubling of the rms unsteadiness seems to have almost no effect on average heat transfer. This important result points out the danger of treating the wake-induced unsteadiness as a simple turbulence intensity.

The insertion of the 3-mesh grid at the $21.0 \mathrm{~cm}$ upstream location produced about a 70 percent increase in the baseline turbulence. This increase shifted all of the spanwise-averaged heat transfer data, both no-rotor and rotor wake, up uniformiy, about 13 percent at stagnation. Curiously, increasing the baseline turbulence appears to have little or no effect on the rms turbulence/ unsteadiness of the rotor wakes, but it does affect the heat transfer. Finally, one notes that increasing the grid turbulence to a modest level of 2.84 percent produces a higher heat transfer level than all the rest of the heat transfer data.

It has become common to express cylinder in crossflow heat transfer data as $N u / \sqrt{R e}$ verses Tu $\sqrt{R e}$. Kestin and Wood (ref. 17) and Lowery and Vachon (ref. 21) proposed quadratic correlations for the stagnation line heat transfer which are often used. Lowery and Vachon (ref. 21) also showed that the same trends as at stagnation existed for overall heat transfer, but, of course, at lower average values. In reference 5 the present authors suggested that over. all heat transfer to a circular cylinder in the wake of a spoked rotor could be correlated in the same manner by treating the rms flucuations behind the rotor as turbulence. Following up on that suggestion, the stagnation gauge data for all cases are shown in these variables on figure 11 along with the data of Lowery and Vachon. The no rotor data agree well with data of Lowery and Vachon. The rotor-wake data do not agree and they do not correlate in these variables. This is not too surprising in light of the previous figure. What was thought to be a correlating trend in reference 5 , was not. The dif ference in the present experimental conditions from the previous is the addi. tion of $3.18 \mathrm{~mm}$ pins. They were not used in reference 5 . Since the larger pins double the rms flucations but make very little effect on the heat trans. fer, Tu' cannot be a correlating parameter. Actually, if one were to ignore the wake and use the grid turbulence level, the data would probably fall within the wide band of the no rotor data, shown in figure 11. This representation would be wrong, however, since the wakes do have an effect on stagnation heat transfer, albeit small. 
The main effect of the wakes on the spanwise average heat transfer is the angular asymmetry. This effect is best shown in figure 12, where the ratio of windward-to-leeward heat transfer is plotted against angle from stagnation for the data of figure 9 . There is quite a bit of scatter in this data, nevertheless clear trends do exist. Lines were drawn roughly through the data to aid in interpretation. In this representation it can be seen clearly that pin size and Strouhal number (rotor speed) make a difference. There appeared to be no special influence of grid turbulence or Reynolds number on this asymmetry. Although there is a definite trend at all angles, at angles below about $40^{\circ}$ the asymmetry was less than 5 percent, which is within the uncertainty. At the lowest Strouhal number, 0.62, the asymmetry ranged from 5 percent with the small pins to 10 percent with the large pins. At the highest strouhal number, 2.51, the asymmetry range was 35 to 50 percent at the higher angles. It should be noted that on an airfoil the circular leading edge is faired smoothly to the rest of the airfoil and thus separation effects are minimized. The large effects seen herein at large angles should not be present on an airfoil but the asymmetry will be present. Further investigation on airfoils is warranted.

\section{CONCLUSIONS}

An experiment was performed in which the wake effects of a turbine stage were simulated using a spoked-wheel rotor and downstream circular cylinder as a stator leading edge. Spanwise average circumferentially local heat transfer coefficients were measured over a range of Reynolds and strouhal numbers and at two levels of grid-generated turbulence. The rotor could be rotated in either direction, resulting in the wakes being convected both into and away from the heated surface. The primary conclusions from this experiment are as follows:

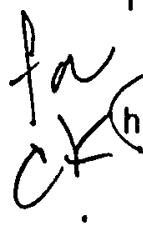

1. The wakes induced by the spoked rotor produce a modest increase in heat transfer over the no-rotor reference case.

2. Increasing the baseline turbulence shifts both the no rotor reference case and the rotor-wake heat transfer data up uniformly.

3. The wake-generated rms unsteadiness is not a correlating parameter and should not be classified as turbulence. The data strongly support the need to separate out the effects of random turbulence and periodic unsteadiness and treat them separately.

4. The convected wakes produce a significant asymmetry in heat transfer around the leading edge of the heated cylinder from the side impacted by the wakes to the side shielded from the wakes. This asymmetry increases with Strouhal number and wake size.

\section{REFERENCES}

1. Dunn, M.G.; Rae, W.J.; and Holt, J.L.: Measurement and Analys is of Heat Flux Data in a Turbine Stage: Part I - Description of Experimental Apparatus and Data Analysis. J. Eng. Gas Turbines Power, vol. 106, no. 1, Jan. 1984, pp. 229-233. 
2. Dunn, M.G.; Rae, W.J.; and Holt, J.L.: Measurement and Analysis of Heat Flux Data in a Turbine Stage: Part II - Discussion of Results and Comparison with Predictions. J. Eng. Gas Turbines Power, vol. 106, no. 1, Jan. 1984, pp. 234-240.

3. Dunn, M.G.: Detalled Heat-Flux Measurements for the Blade Surface in a Full-stage Rotating Turbine. Paper submitted to ASME 31 st Inter. Gas Turbine Conf., Dusseldorf, W. Germany, June 1986.

4. Dring, R.P., et al.: Turbine Rotor-Stator Interaction. J. Eng. Power, vol. 104, no. 4, 0ct. 1982, pp. 729-742.

5. Simoneau, R.J.; Morehouse, K.A.; and Vanfossen, G.J.: Effect of a Rotor Wake on Heat Transfer from a Circular Cylinder. ASME Paper 84-HT-25, Aug. 1984 .

6. Doorly, D.J.; and Oldfield, M.L.G.: Simulation of the Effects of Shock Wave Passing on a Turbine Rotor Blade. ASME Paper 85-G1-112, Mar. 1985.

7. Ashworth, D.A., et al.: Unsteady Aerodynamic and Heat Transfer Processes in a Transonic Turbine Stage. ASME Paper 85-GT-128, Mar. 1985.

8. Bayley, F.J.; and Priddy, W.J.: Effects of Free-Stream Turbulence Intensity and Frequency on Heat Transfer to Turbine Blading. J. Eng. Power, vol. 103, no. 1, Jan. 1981, pp. 60-64.

9. Pfeil, H.; Herbst, R.; and Schroder, T.: Investigation of the Laminar-Turbulent Transistion of Boundary l.ayers Disturbed by Wakes.

J. Eng. Power, vol. 105, no. 1, Jan. 1983, pp. 130-137.

10. Jayaramon, R.; Parikh, P.; and Reynolds, W.C.: An Experimental Study of the Dynamics of an Unsteady Turbulent Boundary Layer. (Tr-18, Stanford Univ.; NASA Contracts ARO-1-80;-2-81;-1-82) NASA CR-170278, 1982.

11. Adamczyk, J.J.: A Model Equation for Simulating Flows in Multistage Turbomachinery. ASME Paper 85-G7-226, Mar. 1985.

12. Evans, R.L.: Turbulence and Unsteadiness Measurements Downstream of a Moving Blade Row. J. Eng. Power, vol. 97, no. 1, Jan. 1975, pp. 131-139.

13. VanFossen, G.J., et al.: Heat Transfer Distributions Around Nominal Ice Accretion Shapes Formed on a Cylinder in the NASA Lewis Icing Research Tunne1. AIAA Paper 84-0017, Jan. 1984.

14. Eckert, E.R.G.; and Drake, R.M.: Heat and Mass Transfer, 2nd ed., McGraw Hill, New York, 1959.

15. Kline, S.J.; and McClintock, F.A.: Describing Uncertainties in Single-Sample Experiments. Mech. Eng., vol. 75, no. 1, Jan. 1953, pp. 3-8.

16. O'Brien, J.E.; and Vanfossen, G.J., Jr.: The Influence of Jet-Grid Turbulence on Heat Transfer from the Stagnation Region of a Cylinder in Crossflow. ASME Paper 85-HT-58. Aug. 1985. 
17. Kestin, J., and Wood, R.T.: The Influence of Turbulence on Mass Transfer from Cylinders. J. Heat Trans., vol. 93, no. 4, Nov. 1971, pp. 321-327.

18. Van Fossen, G.J.: - private communication.

19. Giedt, W.H.: Effect of Turbulence Level of Incident Air Stream on Local Heat Transfer and Skin Friction on a Cylinder. J. Aeronaut. Sci., vol. 18, no. 11, Nov. 1951, pp. 725-730.

20. Pape 11, S.S.: Influence of Thermal Boundary Conditions on Heat Transfer from a Cylinder in Crossflow. NASA TP-1894, 1981.

21. Lowery, G.W.; and Vachon, R.I.: The Effect of Turbulence on Heat Transfer from Heated Cylinders. Int. J. Heat Mass Trans., vol. 18, no. 11, Nov. 1975, pp. 1229-1242. 

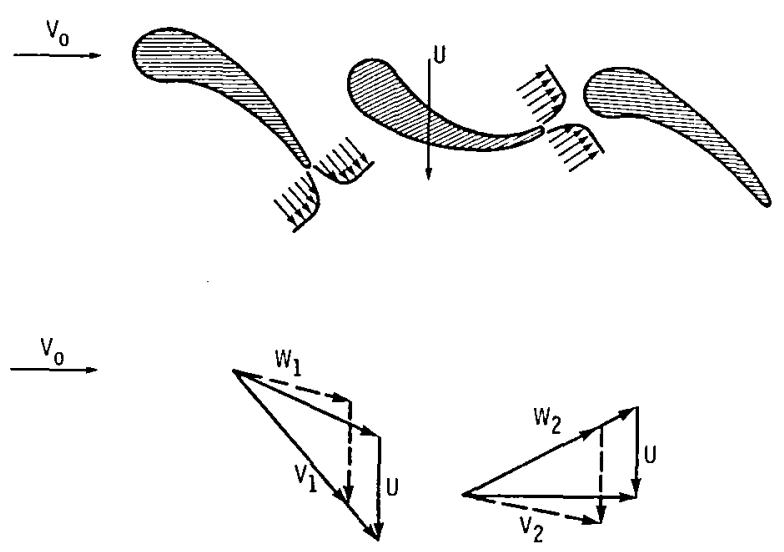

(a) Turbine stage.

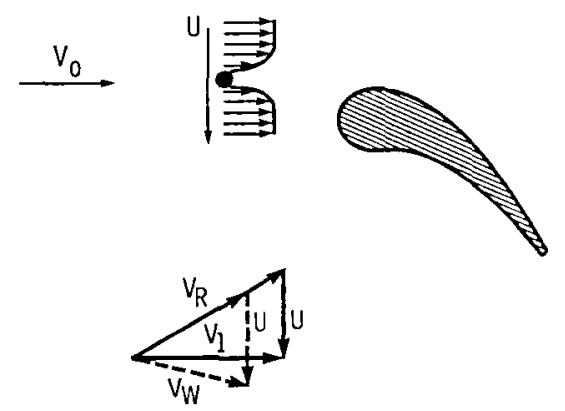

(b) Simulation.

Figure 1. - Simulation of furbine wakes using a spoked wheel disturbance generator.

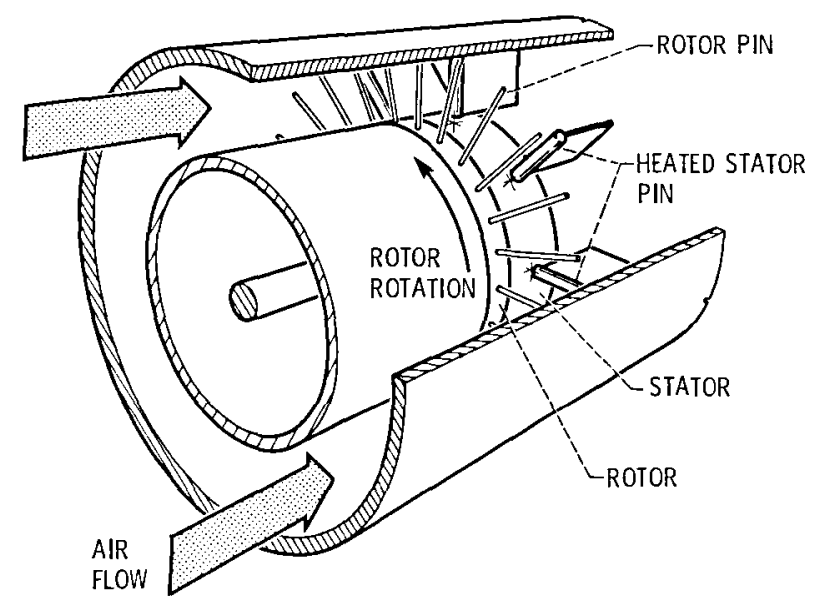

Figure 2 - Cuncept of rotor wake heat transfer experiment. 

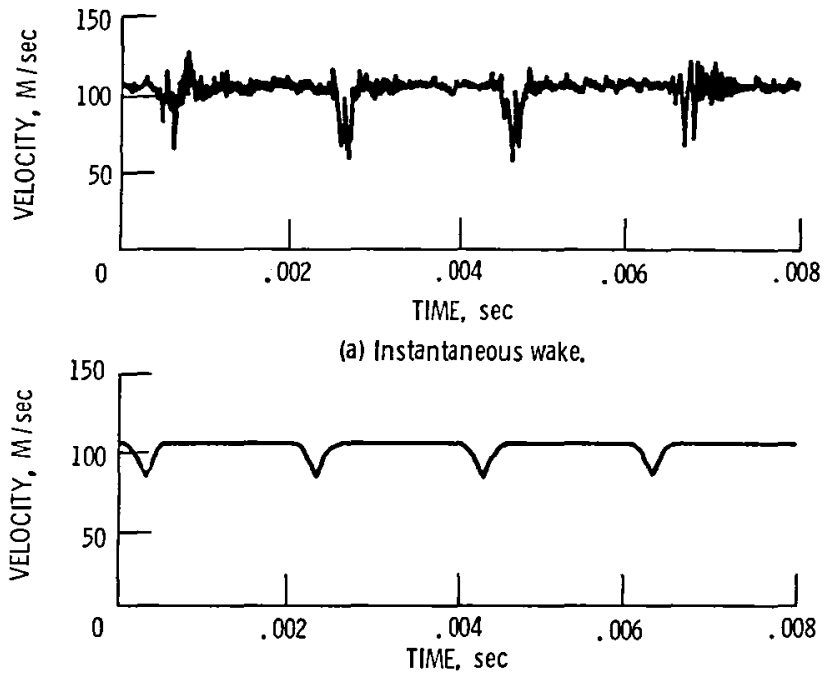

(b) Ensemble averaged wake.

Figure 3. - Typical wakes generated by a spoked wheel disturuance generator.

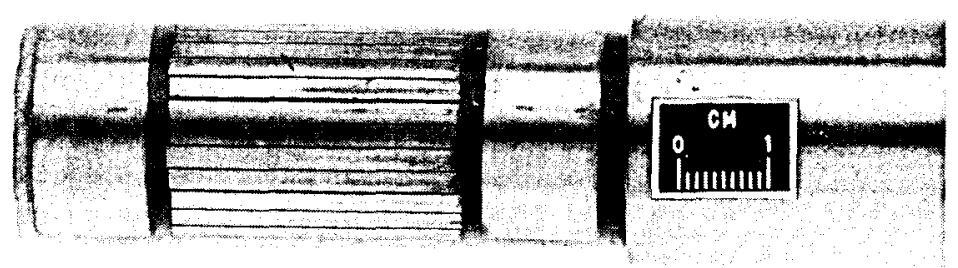

C-84-0797

Figure 4. - Photograph of circumferentially segmented copper heater. 


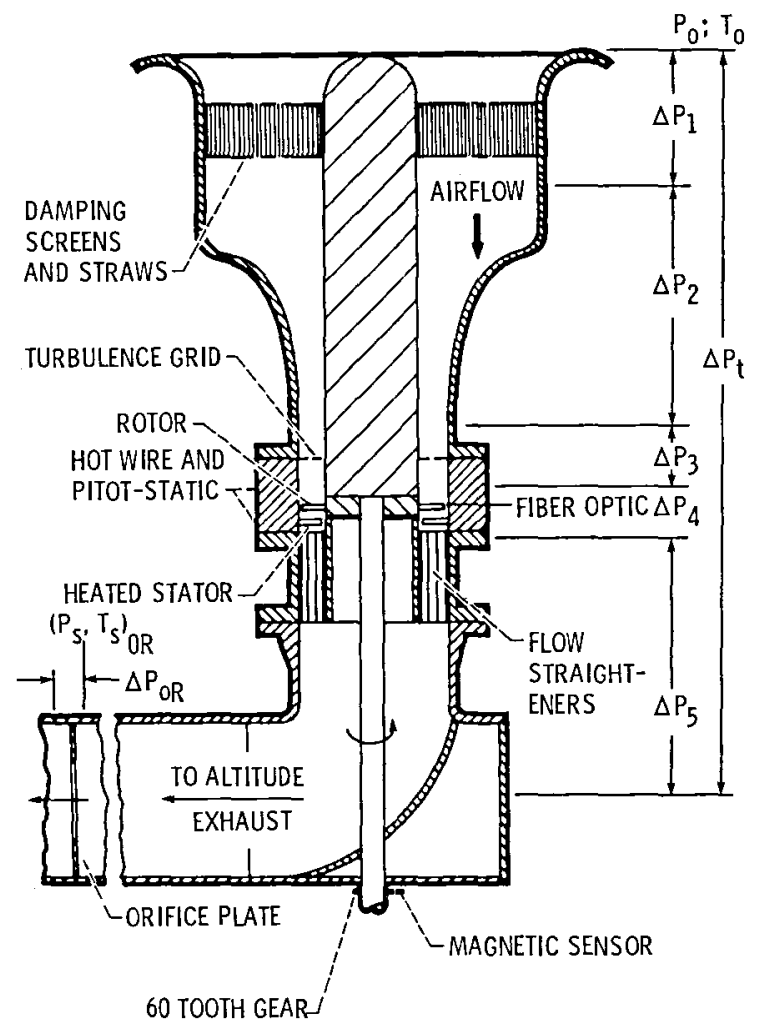

Figure 5. - Rig flow schematic.

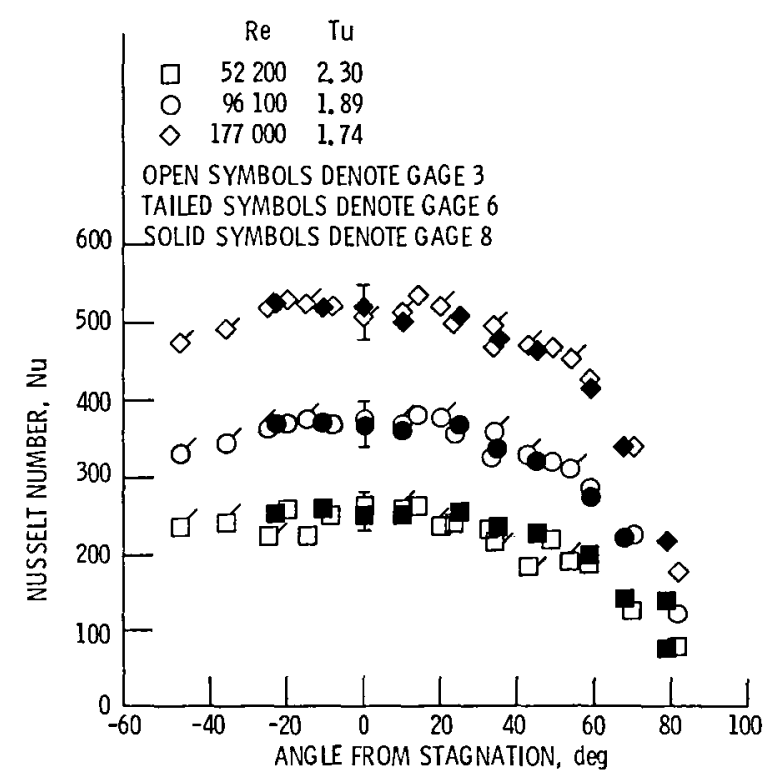

Figure $6_{.}-$Effect of circumiferential position of stagnation gage on Nusselt number distribution. 


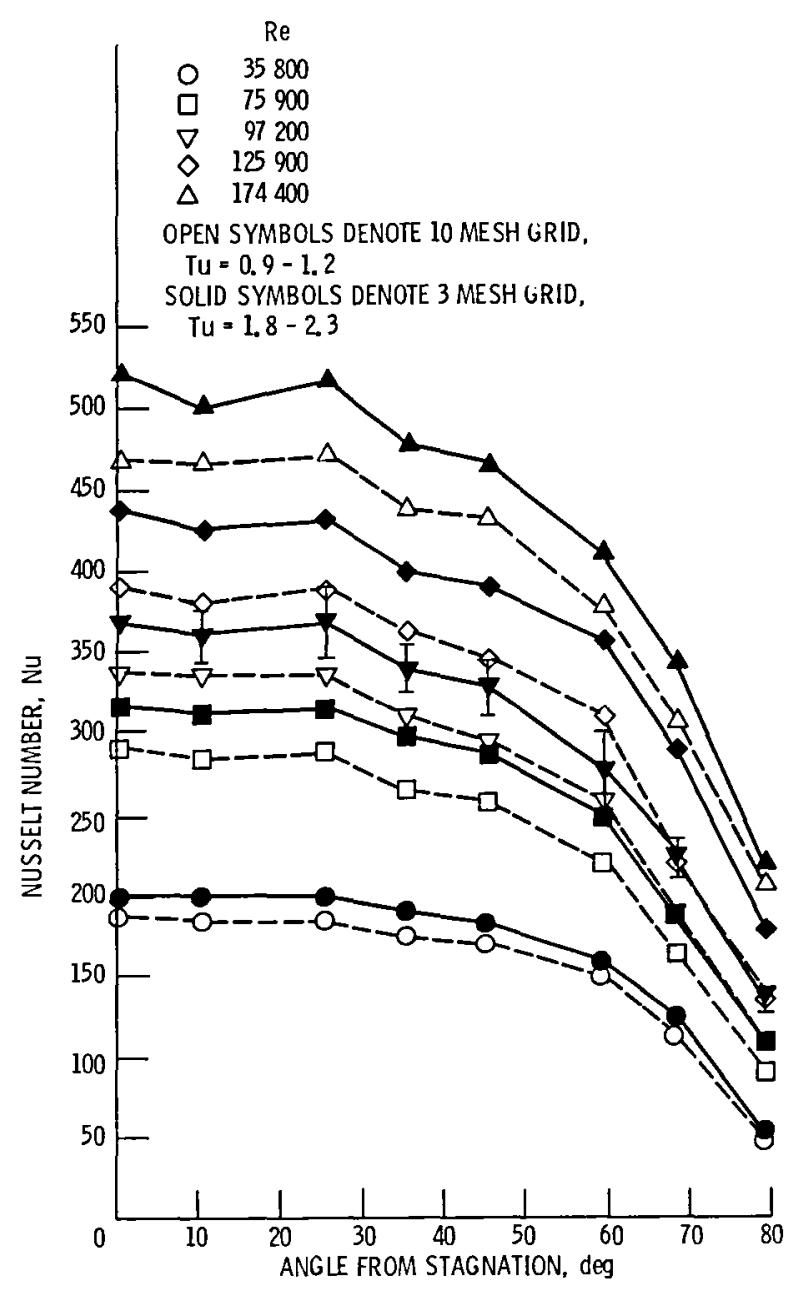

Figure 7. - Spanwise average circumferential Nusselt number distribution as a function of Reynolds number and turbulence level with the rotor remioved. 


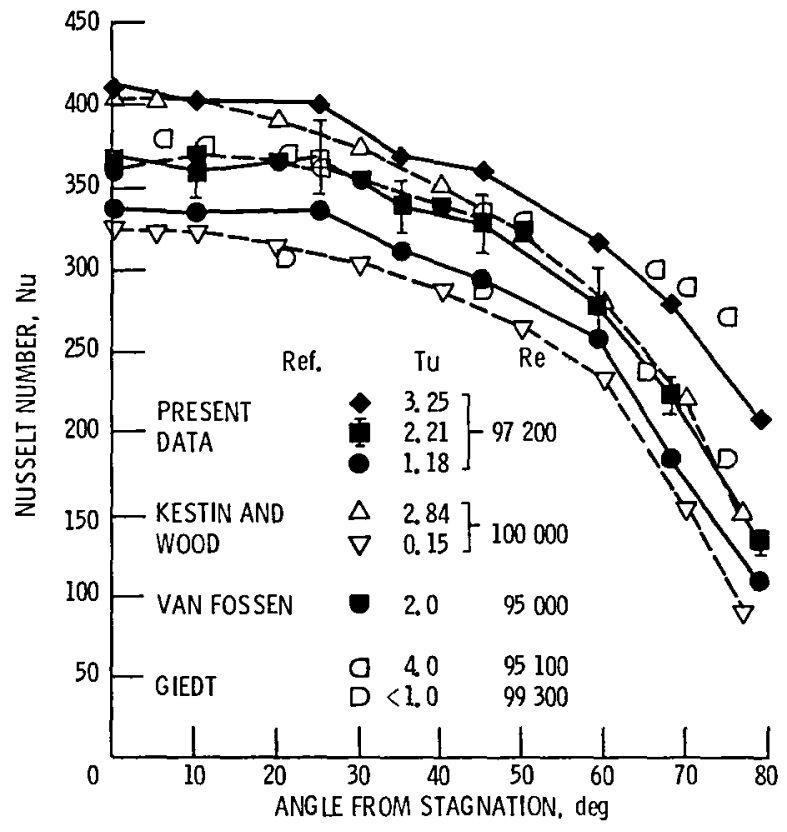

Figure $\delta_{0}$ - Comparison of present data (rotor removed) with other experiments. 


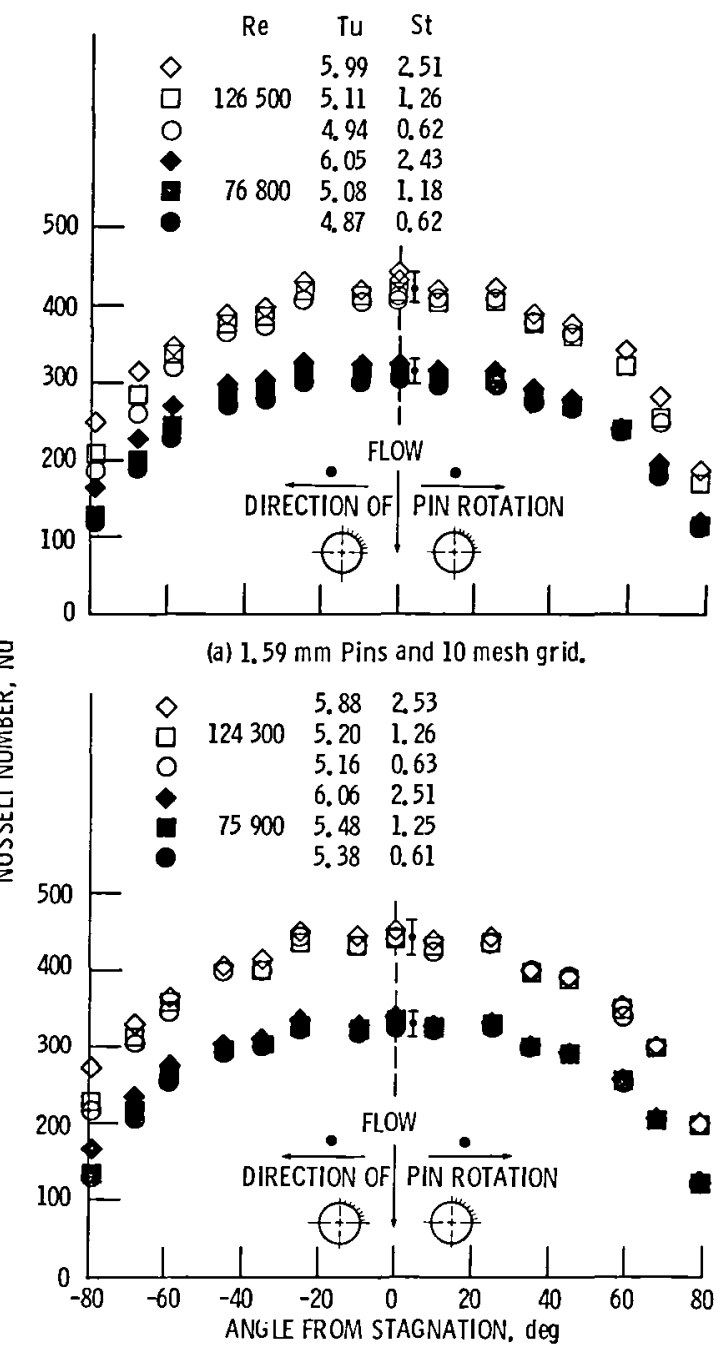

(b) $1.59 \mathrm{~mm}$ Pins and 3 mesh grid.

Figure 9. - Effect rotor pin wakes on spanwise average circumferential heat transfer. 


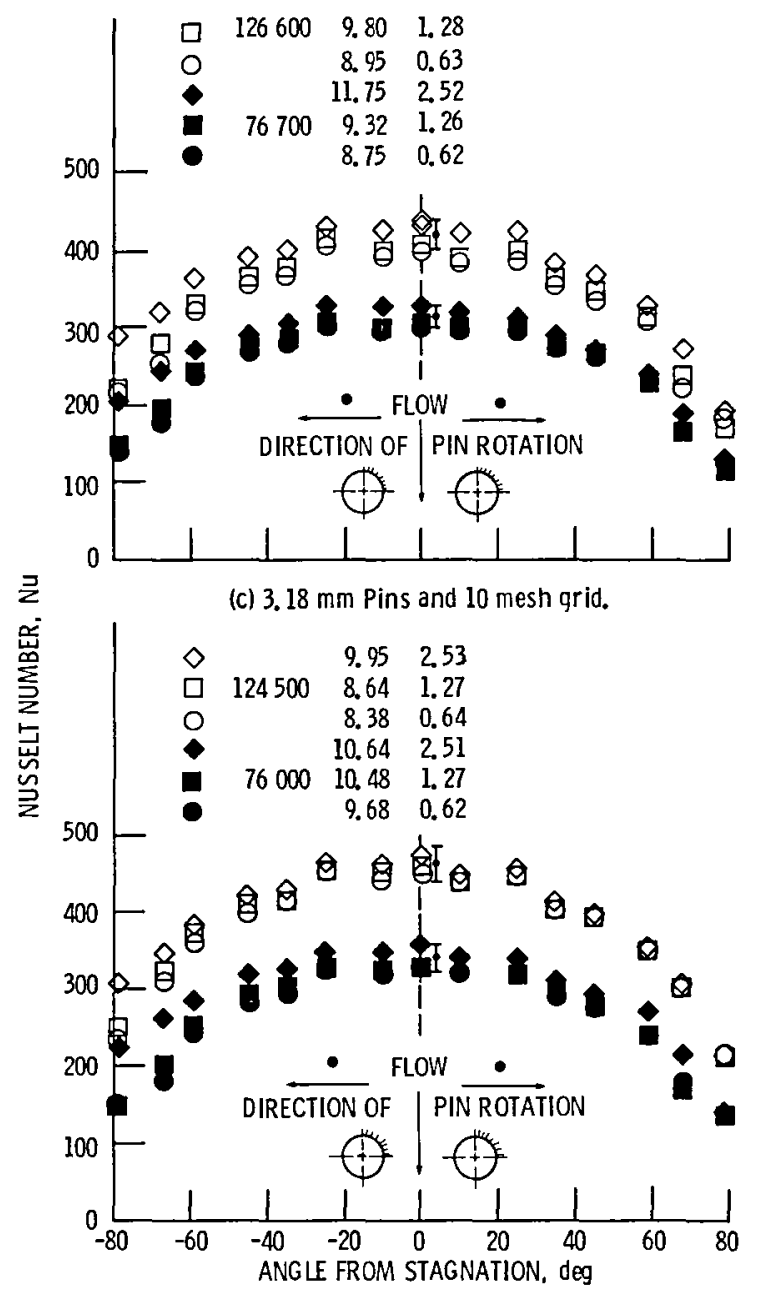

(d) $3.18 \mathrm{~mm}$ Pins and 3 mesh grid.

Figure 9. - Concluded. 


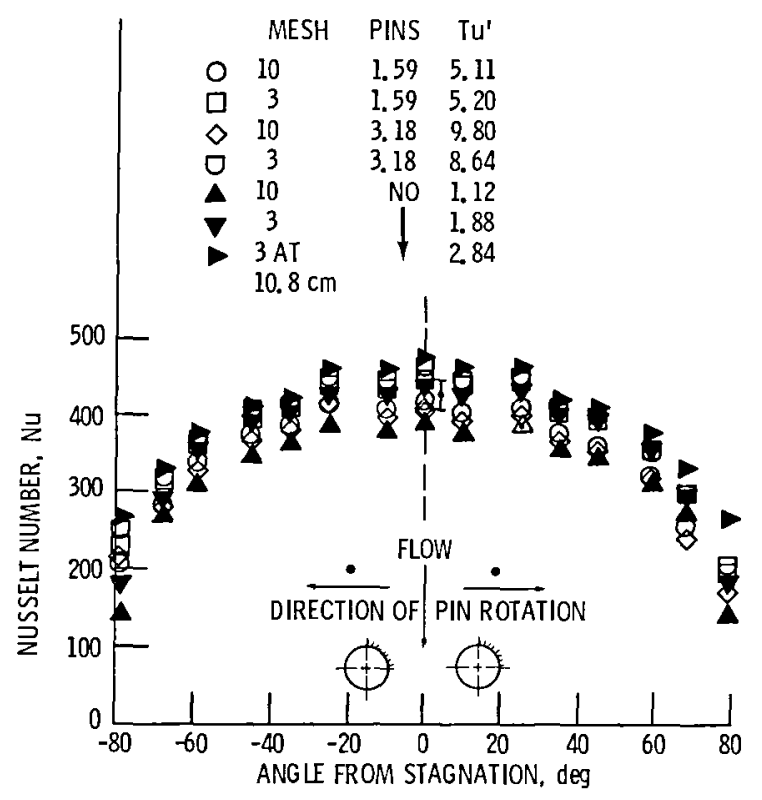

Figure 10. - Effects of various types of unsteadiness on the circumferential distribution of heat transfer.

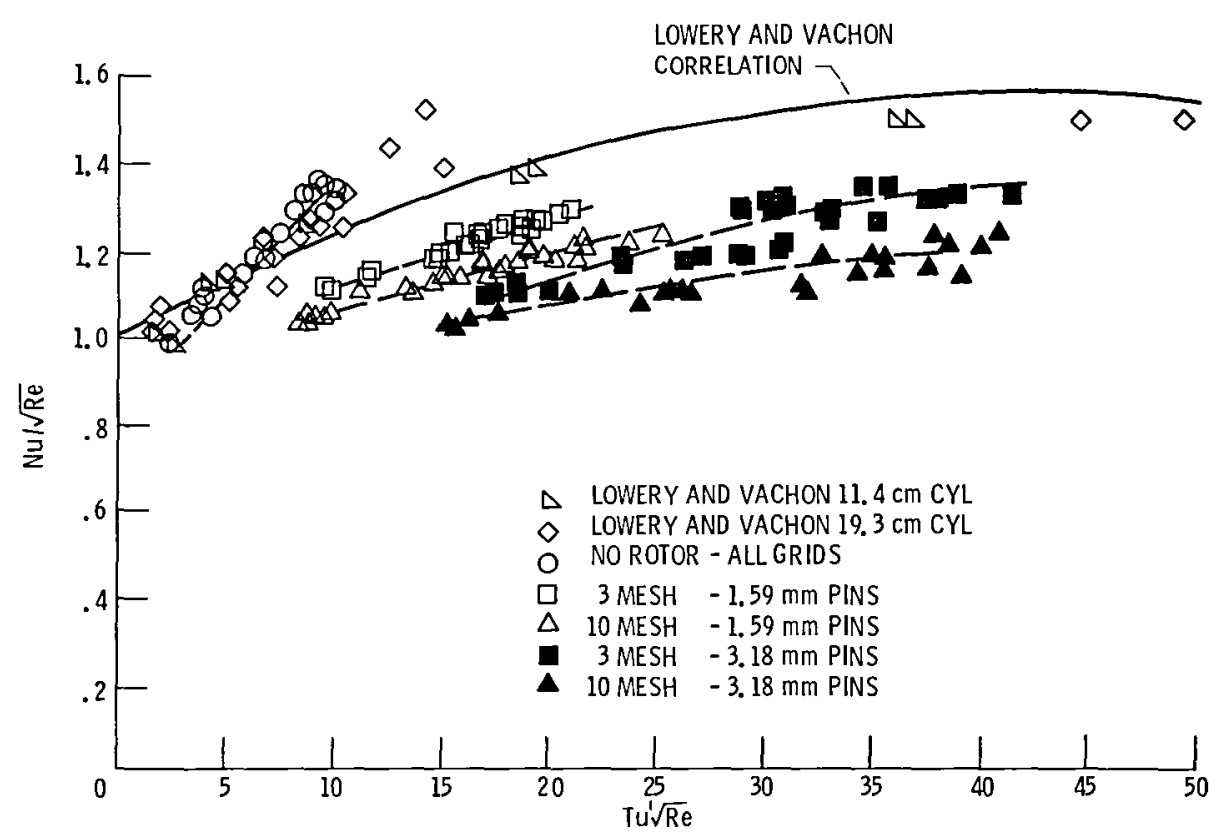

Figure 11. - Comparison of rotor wake stagnation heat transfer data to frequently used sorrelation. 


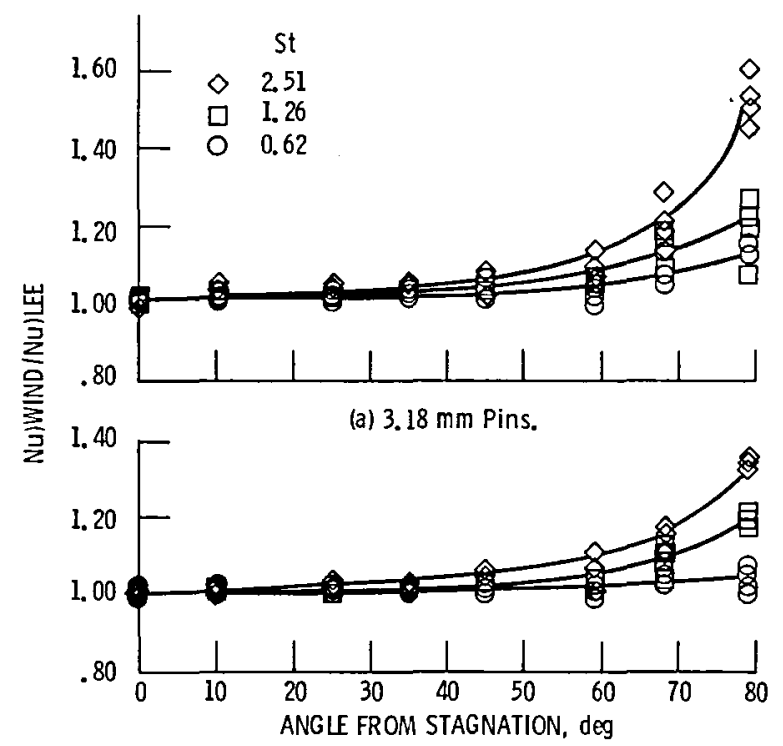

Figure 12 - Heat transfer distribution asymmetry resulting from wake size and rotational speed. 


\begin{tabular}{|c|c|c|c|c|}
\hline $\begin{array}{l}\text { 1. Report No. } \\
\text { NASA TM-87234 }\end{array}$ & \multicolumn{2}{|c|}{ 2. Government Accession No. } & \multicolumn{2}{|c|}{ 3. Recipient's Catalog No. } \\
\hline \multirow{2}{*}{\multicolumn{3}{|c|}{$\begin{array}{l}\text { 4. Title and Subtitle } \\
\text { Effect of a Rotor Wake on the Local Heat Transfer } \\
\text { on the Forward Half of a Circular Cylinder }\end{array}$}} & \multicolumn{2}{|c|}{$\begin{array}{l}\text { 5. Report Date } \\
\text { March } 1986\end{array}$} \\
\hline & & & \multicolumn{2}{|c|}{$\begin{array}{l}\text { 6. Performing Organization Code } \\
505-31-04\end{array}$} \\
\hline \multirow{2}{*}{\multicolumn{3}{|c|}{$\begin{array}{l}\text { 7. Author(s) } \\
\text { Kim A. Morehouse and Robert J. Simoneau }\end{array}$}} & \multicolumn{2}{|c|}{$\begin{array}{l}\text { 8. Performing Organization Report No. } \\
\text { E-2751 }\end{array}$} \\
\hline & & & \multicolumn{2}{|l|}{ 10. Work Unit No. } \\
\hline \multicolumn{3}{|c|}{$\begin{array}{l}\text { 9. Performing Organization Name and Address } \\
\text { National Aeronautics and Space Administration } \\
\text { Lewis Research Center } \\
\text { Cleveland, Ohio } 44135\end{array}$} & \multicolumn{2}{|c|}{ 11. Contract or Grant No. } \\
\hline \multirow{2}{*}{\multicolumn{3}{|c|}{$\begin{array}{l}\text { 12. Sponsoring Agency Name and Address } \\
\text { National Aeronautics and Space Administration } \\
\text { Washington, D.C. } 20546\end{array}$}} & \multicolumn{2}{|c|}{$\begin{array}{l}\text { 13. Type of Report and Period Covered } \\
\text { Technical Memor andum }\end{array}$} \\
\hline & & & \multicolumn{2}{|c|}{ 14. Sponsoring Agency Code } \\
\hline \multicolumn{5}{|c|}{$\begin{array}{l}\text { 15. Supplementary Notes } \\
\text { A shortened version of this report will be presented at the } 8 \text { th International } \\
\text { Heat Transfer Conference, San Francisco, California, August } 17-22,1986 \text {. } \\
\text { Kim A. Morehouse and Robert J. Simoneau, NASA Lewis Research Center. }\end{array}$} \\
\hline \multicolumn{5}{|c|}{ 16. Abstract } \\
\hline \multicolumn{5}{|c|}{$\begin{array}{l}\text { An experiment has been developed to simulate the wake dynamics of a turbine rotor-stator combination. } \\
\text { The experiment consisted of a spoked wheel rotating in annular flow, generating simulated rotor wakes. } \\
\text { The wakes impinged on a simulated stator, composed of a circular cylinder with a splitter plate behind } \\
\text { it. The test rig properly simulated the wake shapes and velocity dynamics of a rotat ing turbine } \\
\text { stage. The focus of the research was spanwise averaged circumferentially local heat transfer in the } \\
\text { circular cylindrical leading edge region of a turbine airfoil. The range of Reynolds number based on } \\
\text { the stator cylinder diameter was } 35000 \text { to } 175000 \text {. The reduced blade passing frequencies, or } \\
\text { Strouhal numbers, also based on the stator cylinder diameter, ranged from } 0.63 \text { to } 2.50 \text {. The wakes } \\
\text { were generated by two different sets of circular cylindrical bars, } 1.59 \text { and } 3 \text {. } 18 \text { mm in diameter. The } \\
\text { rotor could be rotated either clockwise or counterclockwise, causing the wakes to impinge on either } \\
\text { the leeward or the windward side of the heated cylinder. In addition, grid turbulence was introduced } \\
\text { upstream yielding freestream turbulence of } 1.0 \text { to } 2.5 \text { percent at the stator location. The data pre- } \\
\text { sented in this paper, therefore, represent an extensive body of local heat transfer coefficients, } \\
\text { which can be used to develop models in the very important leading edge region of a turbine airfoil. } \\
\text { The wakes produced only a modest increase in heat transfer over the baseline no-rotor data. The data } \\
\text { in the presence of the rotor wakes showed an asymetry from the leeward to the windward side. } \\
\text { Windward-side levels of from } 30 \text { to } 40 \text { percent higher than corresponding lecward-side levels were not } \\
\text { uncommon, particularly at the combination of high strouhal number and larger wake generating pins. } \\
\text { The stagnation gauge data were examined against the TuVRe parameter over a wide range from } 8 \text { to } \\
\text { to, and found not to be fully correlated by this often used parameter. There were distinct trends } \\
\text { with both free-stream turbulence level and wake-generating bar diameter. The results strongly indi- } \\
\text { cate a need to separate the wake influence from turbulence effects. }\end{array}$} \\
\hline $\begin{array}{l}\text { 17. Key Words (Suggested by Auth } \\
\text { Rotor wake; Heat }\end{array}$ & ylinder & $\begin{array}{l}\text { 18. Distributio } \\
\text { Unc las } \\
\text { STAR C }\end{array}$ & ry 34 & \\
\hline $\begin{array}{l}\text { 19. Security Classif. (of this report) } \\
\text { Unc las if ifed }\end{array}$ & $\begin{array}{r}\text { Security Class } \\
\text { U }\end{array}$ & page) & 21. No. of pages & 22. Price* \\
\hline
\end{tabular}


End of Document 